Review

\title{
Decellularized Hydrogels in Bone Tissue Engineering: A Topical Review
}

\author{
Andrea Pacifici ${ }^{1}$, Luigi Laino ${ }^{2}$, Marco Gargari ${ }^{3}$, Federico Guzzo ${ }^{4}$, Andrea Velandia Luz ${ }^{5}$, Antonella \\ Polimeni6, Luciano Pacifici ${ }^{\circledR}$ \\ 1. Department of Oral and Maxillofacial Sciences La Sapienza University of Rome, Italy. \\ 2. Multidisciplinary department of surgical and dental specialties. University of Campania Luigi Vanvitelli \\ 3. Department of Clinical Sciences and Translational Medicine, University of Rome "Tor Vergata", Rome, Italy \\ 4. Department of Dentistry "Fra G.B. Orsenigo", Ospedale San Pietro FBF, Rome, Italy \\ 5. AgEstimation Project, Institute of Legal Medicine, University of Macerata, Macerata, Italy \\ 6. Department of Oral and Maxillofacial Sciences, Sapienza University of Rome, Italy \\ $\triangle$ Corresponding author: Prof. Pacifici Luciano, Department of Oral and Maxillofacial Sciences, Sapienza University of Rome, Italy. Email: \\ prof.lucianopacifici@libero.it \\ (C) Ivyspring International Publisher. This is an open access article distributed under the terms of the Creative Commons Attribution (CC BY-NC) license \\ (https://creativecommons.org/licenses/by-nc/4.0/). See http://ivyspring.com/terms for full terms and conditions.
}

Received: 2017.09.11; Accepted: 2018.02.02; Published: 2018.03.08

\begin{abstract}
Nowadays, autograft and allograft techniques represent the main solution to improve bone repair. Unfortunately, autograft technique is expensive, invasive and subject to infections and hematoma, frequently affecting both donor sites and surgical sites. A recent advance in tissue engineering is the fabrication of cell-laden hydrogels with custom-made geometry, depending on the clinical case. The use of ECM (Extra-Cellular Matrix)-derived Hydrogels from bone tissue is the new opportunity to obtain good results in bone regeneration.

Several micro-engineering techniques and approaches are available to fabricate different cell gradients and zonal structures in hydrogels design, in combination with the advancement in biomaterials selection. In this review, we analyse the stereolithografy, the Bio-patterning, the 3D bioprinting and 3D assembly, the Laser-Induced Forward Transfer Bioprinting (LIFT), the Micro-extrusion bioprinting, the promising Electrospinning technology, the Microfluidics and the Micromolding. Several mechanical properties are taken into account for bone regeneration scaffolds. However, each typology of scaffold presents some advantages and some concerns. The research on biomaterials is the most promising for bone tissue engineering: the new biomimetic materials will allow us to obtain optimal results in the next clinical application of basic research.
\end{abstract}

Key words: Extra Cellular Matrix, bone tissue engineering, Hydrogels

\section{Introduction}

Nowadays, autograft and allograft techniques represent the main solutions to facilitate bone repair. Unfortunately, autograft is expensive, invasive, and subject to infections and hematoma, frequently affecting both donor sites and surgical sites 1-4. Besides, there are several issues related to allografts, such as the possibility to cause an immune reaction followed by a rejection; moreover, the patient can be infected if the graft is contaminated ${ }^{5-8}$.

In the last decade, tissue engineering has focused on the development of a scaffold that emulates ECM composition and physic-biochemical properties ${ }^{9-11}$.
The main challenges in the implementation of scaffolds in the human body are: (i) preserving the strength and stability of the interface during the degradation period and the replacement phase by the natural host tissue, (ii) matching the resorption rates to the repair rates of body tissues developed both for hard tissue implants and tissue engineering scaffolds, (iii) being highly porous to allow for nutrients, oxygen and waste transport, as well as neovascularization/ angiogenesis and bone ingrowth ${ }^{12-14}$.

Starting from the 1990s with the introduction of the hydrogels concept, great interest was focused on 
the discovery of new biomaterials and novel techniques to produce hydrogels for hard and soft tissue regenerative applications ${ }^{15}$. Hydrogel in material science is defined as a polymer or peptide-based gel with a major component represented by water and with a hydrophilic behaviour. The presence of microscopic pores interconnected in the hydrogel allow to adsorb a higher amount of water in comparison with other types of material, thus guaranteeing the migration of cells, nutrients and oxygen to the construct ${ }^{16}$. In addition, the easy modulation of their physicchemical and mechanical properties other than cell entrapment and drug delivery potentially makes this substrate ideal for tissue engineering applications. The structural characteristics such as the biodegradability, the water content, the interconnectivity and the biocompatibility make this material the most suitable one for reproducing the ECM platform ${ }^{17,18}$.

Polymers used to synthesize hydrogel networks can be divided into natural and synthetic polymers. The natural polymers' group includes polysaccharides such as chitosan, alginate, hyaluronic acid, agarose, chondroitin sulphate and gelling gum and proteins such as collagen, fibronectin, fibrin and silk.

The hybrid hydrogels are an attempt to combine the good biocompatibility and biochemical properties of natural polymers with the better mechanical performances of synthetic polymers $3,19,20$.

A recent advance in tissue engineering is the fabrication of cell-laden hydrogels with custom-made geometry that is adaptable to the clinical case thanks to the progress made in manufacturing technology 21-25. (Figure 1)

However, a fully functional, mechanically competent, tissue-engineered bone graft showing clinical success in humans has not been developed yet.

\section{Bone Extra-Cellular Matrix: techniques and mechanical properties}

Different microengineering techniques and approaches are available to fabricate different cell gradients and zonal structures in hydrogels design in combination, with the latest advancements in biomaterials selection.

Stereolithografy is based on a laser source and a three-dimensional-controlled stage. The materials generally used to obtain solid freeform structure are photopolymerizable and non-polymerizable polymers. Two different layering approaches can be adopted: the bottom-up and the top-down approaches. The incorporation of cells in the manufacturing process is difficult and these are usually seeded after construct fabrication ${ }^{26,27}$.

Bio-patterning is based on micromirrors digital technology generating a reflective photomask, which is the guide to synthesize and polymerize the $3 \mathrm{D}$ structure of the scaffold at the same time.

A spatial resolution less of 10 micron allows the encapsulation of cells in the constructs and can be obtained by combining photopatterning and electro-patterning in the design of a microscale hydrogel ${ }^{28-30}$.
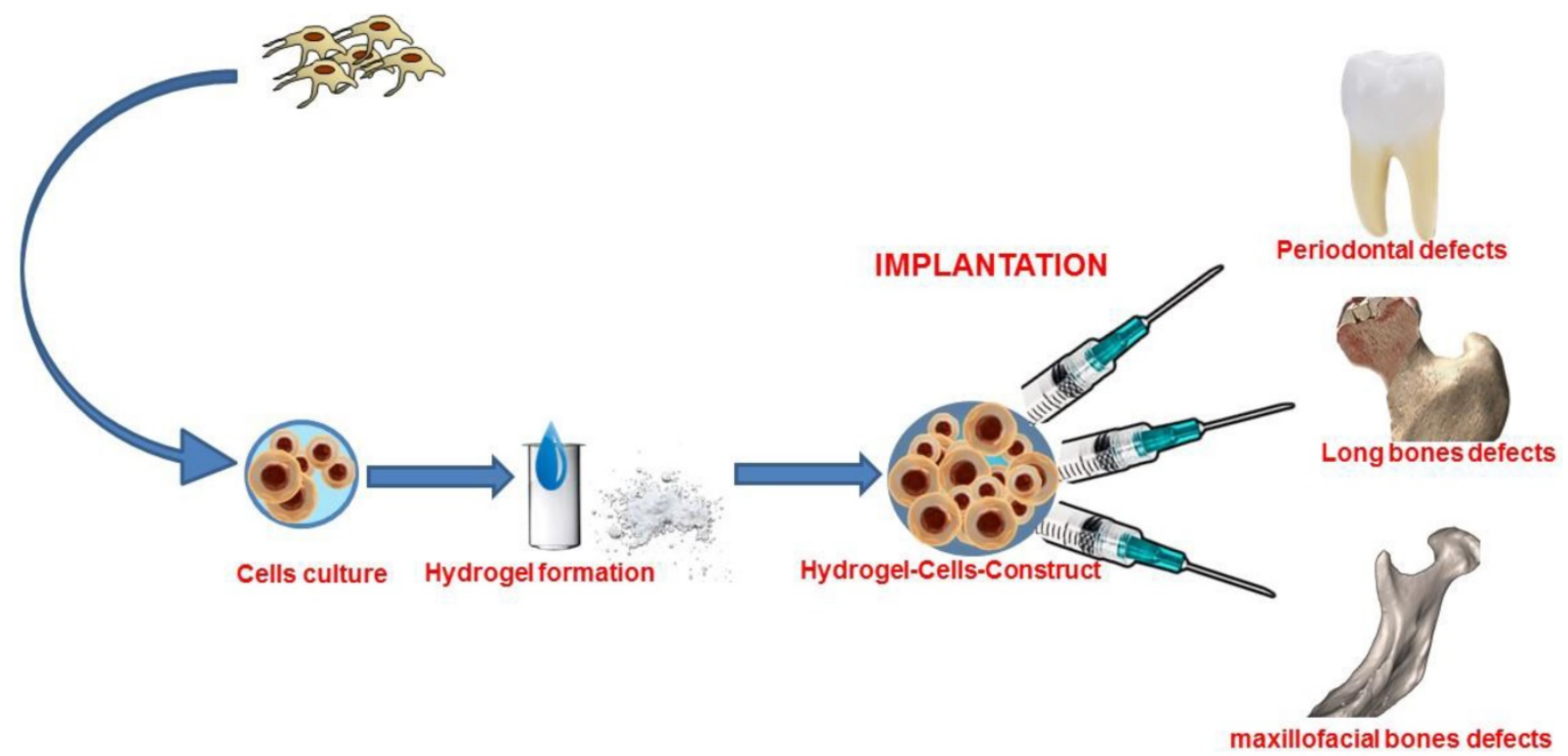

Figure 1. Graphical abstract of bone tissue engineering with stem cells combined with hydrogel form biomaterial. 
3D bioprinting applies a layering deposition mechanism of bio-inks and cells. The instrument is composed of a bio-ink reservoir and a 3D controllable platform. Such printers, which are defined as inkjet, can print through thermal or acoustic approaches, thus setting the amount of bio-ink to be deposited in a certain area and layering the defined prototype. The crosslinking of hydrogel materials can occur through the incorporation, for example, of tyrosinase or through sonication. Cell viability and proliferation have shown to be high when this manufacturing process is used. The drawbacks are the lower thickness obtained as compared with other technologies, the lower resolution at micro and nanoscale length scale as well as the decrease in the mechanical strength and in the ability to withstand degradation and load-bearing defects ${ }^{31-33}$.

Laser-Induced Forward Transfer Bioprinting (LIFT) is based on laser pulses that generate high-pressure bubbles leading the bio-ink through a ribbon into the collector. Several factors affect the final product, such as the viscosity, wettability and free energy surface of the material, the distance between the ribbon and the bio-ink as well as the laser energy. With such technology, the number of ribbons used is related to the number of materials used as bio-inks 34-36.

Micro-extrusion bioprinting is one of the cheapest technologies mentioned in this review. The bio-ink is extruded in a micrometric length scale along the three axes. Two approaches are used depending on the material viscosity, such as the mechanical extrusion for lower viscosities and the pneumatic one for higher viscosities. The resolution performance is better in the mechanical system than in the pneumatic one. In this manufacturing process, the temperature can be regulated, thus limiting side effects in case of cells loading; however, the force generated to extrude the material can lower the cell viability ${ }^{37-39}$.

Electrospinning technology allows the creation of fibers that can adopt a porous or core-shell morphology depending on the type of material being spun as well as the evaporation rates and miscibility of the solvents involved. This technology allows for a higher mechanical performance of the matrix; however, the three-dimensional structure is hard to manage especially compared with the precision of modern 3D-printing technology, therefore it is difficult use of this manufacturing process at an industrial level ${ }^{40,41}$.

Microfluidics is used to produce small and 2D geometries at a centimetre length scale, but it is difficult to use in complex 3D shaping. A passive pump generates a flow induced intake while the evaporation of the prepolymer is induced before the photo-crosslinking step, thus producing layered hydrogels with different cell gradient concentrations 42,43 .

Micro-molding technique utilizes 3D medical-imaging of bone plateau, two-part reverse mold design and fabrication and hydrogel molding. If materials with higher resolution and free energy surface are used, such as fluoro-based materials, the nano-carrier can be incorporated in the scaffold for drug delivery applications. In micro-molding it is difficult to tailor synthetic construction and cell implementation at different gradients ${ }^{44}$.

3D assembly allows to aggregate small single units and to interlock cells, thus obtaining an increase in flexural modulus and withstanding large deformation under compressive strain as well as the enhancement in cell viability and differentiation ${ }^{45}$.

In the scaffold designed for bone tissue regeneration, the mechanical coherence of the structure implanted is an important parameter to determine the final success. Indeed, a fundamental role is played by hydrogel as extracellular matrix simulation. It was demonstrated how stem cells behaviour is dictated by the mechanical performances of the ECM. The most important factors are the elastic modulus of the material and the stiffness. Indeed, it was shown how stem cells possess an enhanced proliferation and multipotency maintenance when cultured on hydrogel with an elastic modulus, similar to bone marrow ${ }^{46-48}$.

Bone defects can be identified in load-bearing and no-loaded defects. In this context, the porosity of the material can play an important role, especially if we consider the size of pores. Interconnectivity is also fundamental for cell migration and proliferation as well as the engraftment of the implant through neovascularization mechanism and nutrients perfusion; such characteristic can lower the mechanical performances ${ }^{3}$.

\section{Mechanical characterization of hydrogel in tissue engineering}

Several mechanical properties are taken into account for bone regeneration scaffolds. Tensile, compression and flexural properties are first considered, as well as swelling/deswelling behaviour and indentation. Other important factors to be analysed are the pore size, the interconnectivity defined as pore morphology and the degree of connections between pores.

Most of the techniques available are invasive and destructive for cell-laden scaffolds in in-vitro simulated conditions. For this reason, other techniques, such as long focal microscopy and 
optical-coherence tomography- based spherical indentation, have been evaluated ${ }^{15}$.

In the field of Materials Sciences, the instrument that is used the most to test materials is called Universal Instron machine. By adapting the machine tools $49-51$ it is possible to carry out different mechanical tests; more in details, the apparatus can perform both compression and tensile tests by changing the hardware interface 52,53. In the compression test, the material is put between two plates. Afterwards, the pressure applied in connection with the distance allows, by means of a numerical model, to analyse the mechanical properties. Anyway, through tensile and compression tests, loaddisplacement data are obtained, which are then converted into stress-strain data by a geometrical relationship. Flexural modulus and failure strength are also calculated. A variation of parameters can be adopted when hydrogel materials are tested; more in details, a time-depending variation of fixed loading conditions can be useful 54,55 .

Among the mechanical characteristics considered in tissue engineering applications, elastic modulus is given by the relation between tensile stress and strain while flexural modulus is given by the relation between bending stress and strain during deformation of the material. Furthermore, tensile strength is the maximum stress immediately before the failure value and the maximum strain is represented by the ductility of the material ${ }^{56-60}$.

The tangent modulus is graphically represented during the compression test by the slope of the stress-strain curve at each strain point; this value provides information about the stiffness of the scaffold.

The Weibull modulus, also known as the shape factor, is correlated to the strength variability of the material selected. The fracture energy is directly proportional to the relation between the stress and the Young's modulus ${ }^{58-61}$.

Another useful mechanical characterization of hydrogels can be obtained by means of the Bulge test. This test is performed by inflating the hydrogel through a window and by recording it through a CCD camera, thus analysing the displacement as a function of the pressure. Afterwards, a finite element method allows to deduce, based on the data acquired, the mechanical properties ${ }^{62,63}$.

The extensometer method foresees the block of the sample between two clamps and the application of a tensile force, thus the elongation at a certain force is plotted and stress-strain data are acquired. These last methods are used to calculate the viscoelastic properties, the flexural modulus, as well as the tensile and yield strength of the material taken into account $\mathbf{6 4 , 6 5}$.

The indentation test in another important test in hydrogel characterization. In this case, the hydrogel is put under compression in a specific localized small area, thus a force-displacement curve is reported with the resulting elastic modulus of the material. In addition, by applying the indenter at a constant depth on the hydrogel surface for a fixed period of time, it is possible to acquire stress relaxation data. Other recent indentation techniques for hydrogels are nanoindentation or atomic force microscopes (AFMs) 66,67. Novel non-destructive techniques are being used, such as the long-focal-microscopy-based spherical microindentation system, which allows for a central indentation by using a sphere with a specific weight and therefore it allows to analyse the displacement in the central deformation area as well as the mechanical and viscoelastic properties of the material 68,69 . In addition to this last method, optical-coherencetomography-based spherical microindentation evaluates the mechanical properties of hydrogel materials through the Hertz contact theory applied on the depth indentation area of a sphere into the material. The micrometer resolution of this three-dimensional imaging technique is based on the interferometric backscattering of a light beam in the material. This technique can also determine the geometry and thickness of the hydrogel analysed 70,71.

In literature, different natural and synthetic materials and different technologies have been reported for the preparation of hydrogels, which can be applied as functional biomaterials but also as carriers of cells by microencapsulation. However, the frequent lack of adequate characterization of the hydrogels and of their components, as well as the incomplete description of the technology, lead to the conclusion that many results of in vitro and in vivo studies are not reliable as they cannot be reproduced 72 .

Therefore, researchers should first characterize properly hydrogel-based materials in order to improve their reliability and usefulness in transplantation.

\section{Conclusions and future insights}

Biomaterials are the most important field of research, particularly in bone tissue applications. The use of safe biomaterials is important to ensure a good control of tissue reply after scaffold transplantation, thus avoiding inflammatory and oxidative reactions, which might cause local and systemic pathological conditions ${ }^{73-76}$. Nowadays, tissue engineering and regenerative medicine are very much based on mesenchymal stem cells: the sources easily obtainable 
are the most preferred by surgeons. Indeed, in the last years the main concern related to the use of mesenchymal stem cells (MSCs) has been the complicated method used to obtain them from the source, which is based on invasive procedures ${ }^{77-79}$. A good approach to effective bone tissue engineering is to combine MSCs and the proper biomaterials in a cell-based construct to induce bone tissue formation ${ }^{80-85}$.

Of course, many surgeons already use in dental and maxillofacial applications platelets-rich matrices, such as PRF and PRP: they are pretty useful and allow to obtain a good bone growth with excellent vascularization, thanks to neo-angiogenetic properties of such blood derived materials ${ }^{86-88}$.

The main advantages in using the new hydrogel-based biomaterials are that they are easy to use, especially in complex surgeries and to replace also extensive bone losses 88 .

Future insights could be related to the use of hydrogels in medicine: their considerable ability to be shape-friendly makes hydrogels ideal for guided bone regeneration of complex defects. Hydrogels are also future scaffolds for localized therapies, in order to treat and regenerate at the same time. It is important to underline that also 3D-printing machines are increasingly improving their ability to print different hydrogels to ensure printed tissues to be transplanted in degenerated organs or damaged tissues. In the future we could use both hydrogels and new materials, such as magnesium alloys, to ensure the mechanical and biological skills that will be crucial to achieve a complex regeneration of both hard and soft tissues.

\section{Competing Interests}

The authors have declared that no competing interests exist.

\section{References}

1. Miller DJ, Smith MV, Matava MJ, et al. Microfracture and osteochondral autograft transplantation are cost-effective treatments for articular cartilage lesions of the distal femur. Am J Sports Med. 2015;43(9):2175-2181.

2. Brydone $A$, Meek D, Maclaine S. Bone grafting, orthopaedic biomaterials, and the clinical need for bone engineering. Proc Inst Mech Eng $\mathrm{H}$. 2010;224:1329-1343.

3. Polo-Corrales L, Latorre-Esteves M, Ramirez-Vick JE. Scaffold Design for Bone Regeneration. J Nanosci Nanotechnol. 2014;14(1):15-56.

4. Myeroff $C$, Archdeacon M. Autogenous bone graft: donor sites and techniques. J Bone Joint Surg Am. 2011;93:2227-36.

5. Oppenheim J, Segal D, Spitzer D. Persistent iliac crest donor site pain: independent outcome assessment. Neurosurgery. 2002;51:854-855.

6. Silber J, Anderson D, Daffner S, et al. Donor site morbidity after anterior iliac crest bone harvest for single-level anterior cervical discectomy and fusion. Spine. 2003;28:134-39.

7. Mankin H, Hornicek F, Raskin K. Infection in massive bone allografts. Clin Orthop Relat Res. 2005;432:210-6.

8. Graham S, Leonidou A, Aslam-Pervez N, et al. Biological therapy of bone defects: the immunology of bone allo-transplantation. Expert Opin Biol Ther. 2010;10:885-901.

9. Baker EL, Bonnecaze RT, Zaman MH. Extracellular matrix stiffness and architecture govern intracellular rheology in cancer. Biophys J. 2009;97(4):1013-1021
10. Hong $\mathrm{H}, \mathrm{McC}$ cullough $\mathrm{CM}$, Stegemann JP. The role of ERK signaling in protein hydrogel remodeling by vascular smooth muscle cells. Biomaterials. 2007;28(26):3824-3833.

11. Tibbitt MW, Anseth KS. Hydrogels as extracellular matrix mimics for 3D cell culture. Biotechnol Bioeng. 2009;103:655-663.

12. Chan BP, Leong KW. Scaffolding in tissue engineering: general approaches and tissue-specific considerations. Euro Spine J. 2008;17(4):467-479.

13. Cheunga HY, Laua KT, Lub TP, et al. A critical review on polymer-based bio-engineered materials for scaffold development. Compos Part B: Eng. 2007; 38(3):291-300.

14. Barnesa CP, Sella SA, Bolanda ED, et al. Nanofiber technology: Designing the next generation of tissue engineering scaffolds. Adva Drug Delivery Rev. 2007; 59(14):1413-1433.

15. Geckil H, Xu F, Zhang $\mathrm{X}$, et al. Engineering hydrogels as extracellular matrix mimics. Nanomedicine (Lond). 2010; 5:469-484.

16. Peppas NA, Hilt JZ, Khademhosseini A, et al. Hydrogels in biology and medicine: from molecular principles to bionanotechnology. Adv Mater. 2006;18:1345.

17. Wenger MP, Bozec L, Horton MA, et al. Mechanical properties of collagen fibrils. Biophys J. 2007;93(4):1255-1263.

18. Rivest $\mathrm{C}$, Morrison DWG, Ni B, et al. Microscale hydrogels for medicine and biology: synthesis, characterisation and applications. J Mechanics Materials Structures. 2007;2:1103-1119.

19. Radhakrishnan J, Subramanian A, Krishnan UM, et al. Injectable and 3D Bioprinted Polysaccharide Hydrogels: From Cartilage to Osteochondral Tissue Engineering. Biomacromolecules. 2017;18(1):1-26.

20. Yang J, Shrike Zhang Y, Yue K, et al. Cell-Laden Hydrogels for Osteochondral and Cartilage Tissue Engineering. Acta Biomater. 2017: 57:1-25

21. Yue K, Trujillo-de Santiago G, Alvarez MM, et al. Synthesis, properties, and biomedical applications of gelatin methacryloyl (GelMA) hydrogels. Biomaterials. 2015;73:254-71

22. Nuernberger S, Cyran N, Albrecht $\mathrm{C}$, et al. The influence of scaffold architecture on chondrocyte distribution and behavior in matrix-associated chondrocyte transplantation grafts. Biomaterials. 2011;32(4):1032-1040

23. Dehne T, Karlsson C, Ringe J, et al. Chondrogenic differentiation potential of osteoarthritic chondrocytes and their possible use in matrix-associated autologous chondrocyte transplantation. Arthritis Res Ther. 2009;11(5): R133

24. Amini AA, Nair LS. Injectable hydrogels for bone and cartilage repair. Biomed Mater. 2012;7(2):024105

25. Spiller KL, Maher SA, Lowman AM. Hydrogels for the repair of articular cartilage defects. Tissue Eng Part B Rev. 2011;17(4):281-299

26. Melchels FPW, Feijen J, Grijpma DW. A review on stereolithography and its applications in biomedical engineering. Biomaterials. 2010;31(24):6121-6130.

27. Castro NJ, O'Brien J, Zhang LG. Integrating biologically inspired nanomaterials and table-top stereolithography for 3D printed biomimetic osteochondral scaffolds. Nanoscale. 2015;7(33): 14010.

28. Grogan SP, Chung PH, Soman P, et al. Digital micromirror device projection printing system for meniscus tissue engineering. Acta Biomater. 2013;9(7):7218-26.

29. Guo M, Qu X, Zhu W, et al. Bio-inspired detoxification using 3D-printed hydrogel nanocomposites. Nat Commun. 2014;5:3774.

30. Nichol JW, Khademhosseini A. Modular tissue engineering: engineering biological tissues from the bottom up. Soft Matter. 2009;5:1312-1319.

31. Klebe RJ. Cytoscribing. A method for micropositioning cells and the construction of two- and three-dimensional synthetic tissues. Exp Cell Res. 1988; 179(2): 362-373.

32. Singh $M$, Haverinen $\mathrm{HM}$, Dhagat $\mathrm{P}$, et al. Inkjet printing process and its applications. Adv Mater. 2010;22(6):673-85.

33. Das S, Pati F, Choi YJ, et al. Bioprintable, cell-laden silk fibroin-gelatin hydrogel supporting multilineage differentiation of stem cells for fabrication of three-dimensional tissue constructs. Acta Biomater. 2015;11: 233-246.

34. Tatullo M, Codispoti B, Pacifici A, et al. Potential Use of Human Periapical Cyst-Mesenchymal Stem Cells (hPCy-MSCs) as a Novel Stem Cell Source for Regenerative Medicine Applications. Front Cell Dev Biol. 2017;5:103.

35. Mézel C, Souquet A, Hallo L, et al. Bioprinting by laser-induced forward transfer for tissue engineering applications: Jet formation modeling. Biofabrication. 2010;2(1):014103.

36. Ali M, Pages E, Ducom A, et al. Controlling laser-induced jet formation for bioprinting mesenchymal stem cells with high viability and high resolution. Biofabrication. $2014 ; 6(4): 045001$.

37. Ragaert K, Cardon L, Dekeyser A, et al. Machine design and processing considerations for the 3D plotting of thermoplastic scaffolds. Biofabrication. 2010;2(1):014107.

38. Zhang $X$, Zhang Y. Tissue engineering applications of three-dimensional bioprinting. Cell Biochemistry and Biophysics. 2015;72(3): 777-782.

39. Malda J, Visser J, Melchels F P, et al. Engineering hydrogels for biofabrication. Adv Mater. 2013;25(36): 5011-5028.

40. Liang D, Hsiao BS, Chu B. Functional electrospun nanofibrous scaffolds for biomedical applications. Adv Drug Deliv Rev. 2007:59(14):1392-412.

41. Chen M, Le DQ, Hein S, et al. Fabrication and characterization of a rapid prototyped tissue engineering scaffold with embedded multicomponent matrix for controlled drug release. Int J Nanomedicine. 2012;7:4285-97.

42. Phillips JE, Burns KL, Le Doux JM, et al. Engineering graded tissue interfaces. PNAS. 2008;105(34):12170-12175. 
43. Marrelli M, Maletta $\mathrm{C}$, Inchingolo F, et al. Three-point bending tests of zirconia core/veneer ceramics for dental restorations. Int J Dent. 2013;2013:831976.

44. Ling Y, Rubin J, Deng Y, et al. A cell-laden microfluidic hydrogel. Lab Chip. 2007;7(6):756-62

45. Nover AB, Jones BK, Yu WT, et al. A puzzle assembly strategy for fabrication of large engineered cartilage tissue constructs. J Biomechan. 2016; 49(5):668-677.

46. Annabi N, Nichol JW, Zhong $X$, et al. Controlling the Porosity and Microarchitecture of Hydrogels for Tissue Engineering. Tissue Eng Part B Rev. 2010; 16: 371-383.

47. Halder G, Dupont S, Piccolo S. Transduction of mechanical and cytoskeletal cues by YAP and TAZ. Nat Rev Mol Cell Biol. 2012; 13:591-600.

48. Winer JP, Janmey PA, McCormick ME, et al. Bone marrow-derived human mesenchymal stem cells become quiescent on soft substrates but remain responsive to chemical or mechanical stimuli. Tissue Eng Part A. 2009; 15:147-154.

49. Boeckler AF, Ehring C, Morton D, et al. Corrosion of dental magnet attachments for removable prostheses on teeth and implants. J Prosthodont. 2009;18(4):301-8

50. Yiu EY, Fang DT, Chu FC, et al. Corrosion resistance of iron-platinum magnets. J Dent. 2004 Aug;32(6):423-9.

51. Ansari MY, Agarwal DK, Gupta A et al. Shear Bond Strength of Ceramic Brackets with Different Base Designs: Comparative In-vitro Study. J Clin Diagn Res. 2016 Nov;10(11):ZC64-ZC68

52. Dalaie K, Mirfasihi A, Eskandarion S, et al. Effect of bracket base design on shear bond strength to feldspathic porcelain. Eur J Dent. 2016;10(3):351-5.

53. Tatullo M, Marrelli M, Amantea M, et al. Bioimpedance Detection of Oral Lichen Planus Used as Preneoplastic Model. J Cancer. 2015;6(10):976-83.

54. Svensson A, Nicklasson E, Harrah T, et al. Bacterial cellulose as a potential scaffold for tissue engineering of cartilage. Biomaterials. 2005; 26:419-431.

55. Awad HA, Quinn Wickham M, Leddy HA, et al. Chondrogenic differentiation of adipose-derived adult stem cells in agarose, alginate and gelatin scaffolds. Biomaterials 2004; 25:3211-3222.

56. Bregnocchi A, Zanni E, Uccelletti D, et al. Graphene-based dental adhesive with anti-biofilm activity. J Nanobiotechnology. 2017 ;15(1):89.

57. Niu L-N, Jiao K, Qi Y-P, et al. Intrafibrillar silicification of collagen scaffolds for sustained release of stem cell homing chemokine in hard tissue regeneration. FASEB J. 2012;26:4517.

58. Gong J, Li S, Zhang D, et al. High quality self-assembly magnetite ( $\mathrm{Fe}(3) \mathrm{O}(4))$ chain-like core-shell nanowires with luminescence synthesized by a facile one-pot hydrothermal process. Chem Commun (Camb). 2010;46(20):3514-6.

59. da Fonseca Roberti Garcia L, Pontes EC, Basso FG, et al. Transdentinal cytotoxicity of resin-based luting cements to pulp cells. Clin Oral Investig. 2016;20(7):1559-66.

60. Le JL, Bazant ZP. Strength distribution of dental restorative ceramics: finite weakest link model with zero threshold. Dent Mater. 2009;25(5):641-8

61. Dhandayuthapani B, Poulose AC, Nagaoka Y, et al. Biomimetic smart nanocomposite: in vitro biological evaluation of zein electrospun fluorescent nanofiber encapsulated CdS quantum dots. Biofabrication. 2012;4(2):025008.

62. Ranta-Eskola AJ. Use of the hydraulic bulge test in biaxial tensile testing. Int J Mech Sci. 1979; 21:457-465

63. Tsakalakos T. The bulge test: A comparison of the theory and experiment for isotropic and anisotropic films. Thin Solid Films. 1981; 75:293-305.

64. Drury JL, Dennis RG, Mooney DJ. The tensile properties of alginate hydrogels. Biomaterials. 2004; 25:3187-3199.

65. Jeffrey L, Hinkley A, Morgret LD, et al. Tensile properties of two responsive hydrogels. Polymer. 2004; 45:8837-8843.

66. Ahearne M, Yang Y, El Haj AJ, et al. Characterizing the viscoelastic properties of thin hydrogel-based constructs for tissue engineering applications. J R Soc Interface. 2005; 2:455-463.

67. Mirshams RA, Pothapragada RM. Correlation of nanoindentation measurements of nickel made using geometrically different indenter tips. Acta Mater. 2006; 54:1123-1134.

68. Liu KK, Ju BF. A novel technique for mechanical characterization of thin elastomeric membrane. J Phys D. 2001; 34:L91-L94.

69. Ju BF, Lui KK. Characterizing viscoelastic properties of thin elastomeric membrane. Mech Mater. 2002; 34:485-491.

70. Yang Y, Bagnaninchi PO, Ahearne $\mathrm{M}$, et al. A novel optical coherence tomography-based micro-indentation technique for mechanical characterization of hydrogels. J R Soc Interface. 2007; 4:1169-1173.

71. Kaluzy BJ, Kaluzny JJ, Szkulmowska A, et al. Spectral optical coherence tomography: a novel technique for cornea imaging. Cornea. 2006; 25:960-965.

72. Mahou R, Passemard S, Carvello M, et al. Contribution of polymeric materials to progress in xenotransplantation of microencapsulated cells: a review. Xenotransplantation. 2016;23(3):179-201.

73. Tatullo M, Marrelli M, Scacco S, et al. Relationship between oxidative stress and "burning mouth syndrome" in female patients: a scientific hypothesis. Eur Rev Med Pharmacol Sci. 2012;16(9):1218-21.

74. Inchingolo F, Marrelli M, Annibali S, et al. Influence of endodontic treatment on systemic oxidative stress. Int J Med Sci. 2013;11(1):1-6.

75. Tatullo M, Simone GM, Tarullo F, et al. Antioxidant and Antitumor Activity of a Bioactive Polyphenolic Fraction Isolated from the Brewing Process. Sci Rep. $2016 ; 6: 36042$
76. Marrelli M, Paduano F, Tatullo M. Cells isolated from human periapical cysts express mesenchymal stem cell-like properties. Int J Biol Sci. 2013; 9(10):1070-8.

77. Marrelli M, Paduano F, Tatullo M. Human Periapical Cyst-Mesenchymal Stem Cells Differentiate into Neuronal Cells. J dent res. 2015; 94(6):843-52.

78. Tatullo M, Marrelli M, Paduano F. The regenerative medicine in oral and maxillofacial surgery: the most important innovations in the clinical application of mesenchymal stem cells. Int j med sci. 2015;12(1):72.

79. Tatullo M, Falisi G, Amantea M, et al. Dental pulp stem cells and human periapical cyst mesenchymal stem cells in bone tissue regeneration: Comparison of basal and osteogenic differentiated gene expression of a newly discovered mesenchymal stem cell lineage. J Biol Regul Homeost Agents. 2015;29(3):713-8.

80. Tatullo M, Marrelli M, Falisi G, et al. Mechanical influence of tissue culture plates and extracellular matrix on mesenchymal stem cell behavior: A topical review. Int J Immunopathol Pharmacol. 2016;29(1):3-8.

81. Marrelli M, Falisi G, Apicella A, et al. Behaviour of dental pulp stem cells on different types of innovative mesoporous and nanoporous silicon scaffolds with different functionalizations of the surfaces. J Biol Regul Homeost Agents. 2015;29(4):991-7.

82. Paduano F, Marrelli M, White LJ, et al. Odontogenic differentiation of human dental pulp stem cells on hydrogel scaffolds derived from decellularized bone extracellular matrix and collagen type I. PloS one. 2016;11(2):e0148225.

83. Marrelli M, Pujia A, Palmieri F, et al. Innovative approach for the in vitro research on biomedical scaffolds designed and customized with CAD-CAM technology. Int J Immunopathol Pharmacol. 2016;29(4):778-83.

84. Paduano F, Marrelli M, Palmieri F, et al. CD146 expression influences periapical cyst mesenchymal stem cell properties. Stem Cell Rev. 2016;12(5):592-603

85. Marrelli M, Tatullo M. Influence of PRF in the healing of bone and gingival tissues. Clinical and histological evaluations. Eur Rev Med Pharmacol Sci. 2013;17(14):1958-62.

86. Perniconi B, Coletti D, Aulino P, et al. Muscle acellular scaffold as a biomaterial: effects on $\mathrm{C} 2 \mathrm{C} 12$ cell differentiation and interaction with the murine host environment. Front Physiol. 2014:5:354.

87. Staffoli S, Romeo U, Amorim RNS, et al. The effects of low level laser irradiation on proliferation of human dental pulp: a narrative review. Clin Ter. 2017;168(5):e320-e326.

88. Marrelli M, Gentile S, Palmieri F, et al. Correlation between Surgeon's experience, surgery complexity and the alteration of stress related physiological parameters. PLoS One. 2014; 9(11):e112444. 